\title{
Guardiões das Águas Mirins: Integrando Experiências de Preservação de Recursos Hídricos e Educação Ambiental no Município de Tenente Portela-RS
}

\author{
Guardians of Junior Water Integrating Experiences of Water Resources Preservation and Environmental Education in the \\ Municipality Tenente Portela-RS
}

Kelly Kern Folle ${ }^{1}$, Damaris Kirsch Pinheiro ${ }^{2}$

${ }^{1}$ Bióloga, Especialista do Curso de Especialização em Educação Ambiental, UFSM- Santa Maria, RS, Brasil

2 Engenheira Química, Departamento de Engenharia Química, UFSM - Santa Maria, RS, Brasil (Orientadora)

\section{Resumo}

O aumento da população e das atividades econômicas vem impondo consequências ambientais negativas à realidade mundial, que resultam em perdas na qualidade e na quantidade dos recursos hídricos. Frente a isso, a Educação Ambiental aparece como norteadora de mudanças de conceitos e posturas. Esta pesquisa teve como objetivo promover o fomento de práticas de conservação, preservação e recuperação de recursos hídricos na escola, através do acompanhamento das ações do Projeto Piloto Guardiões das Águas Mirins no Município de Tenente Portela - RS, desenvolvidas com os alunos da Escola Estadual de Ensino Fundamental General Osório. Adotou-se a pesquisa-ação como metodologia. Nesta pesquisa, os participantes deixaram de ser objeto de estudos para serem pesquisadores e produtores de conhecimento de sua própria realidade. A formação e a capacitação dos professores para trabalhar a Educação Ambiental em todas as áreas do ensino foram de suma importância, desta maneira as atividades realizadas com os alunos se apresentaram como instrumentos eficazes para se conseguir criar e aplicar formas de interação sociedade-natureza. Verificou-se, com esta iniciativa, resultados otimizados, através da sensibilização dos alunos e da comunidade escolar as ações foram viáveis na melhoria do ambiente local conduzindo na preservação e no cuidado com os recursos hídricos.

Palavras-chave: Água, Educação Ambiental e Cidadania.

\begin{abstract}
The increase in population and economic activity has imposed negative environmental consequences to the global reality, resulting in losses in quality and quantity of water resources. Faced with this, environmental education appears as guiding changes of concepts and attitudes. This research aimed to promote the spread of practices of conservation, preservation and restoration of water resources in the school, by monitoring the actions of the Pilot Pony Keepers of the Waters in the City of Tenente Portela - RS developed with students at the State College of Education Primary General Osório. The adopted action research as a methodology. In this research, participants no longer the object of study for researchers and producers are aware of their own reality. The education and training of teachers to work in environmental education in all areas of education were paramount, thus the activities with students accounted effective tools to successfully create and implement ways of interaction between society and nature. It was found optimal results this initiative by raising awareness of the students and school community shares were viable in improving the local environment leading to the preservation and care of water resources.
\end{abstract}

Key words: Water, Environmental Education and Citizenship. 


\section{Introdução}

A água possui um valor inestimável. Além de ser um insumo indispensável à produção, e um recurso estratégico para o desenvolvimento econômico, a água constitui um fator determinante na manutenção dos ciclos biológicos, geológicos e químicos que garantem equilíbrio aos ecossistemas. É ainda um bem cultural e social indispensável à sobrevivência e à qualidade de vida da população (DE FREITAS, 2007).

Contudo, sua distribuição entre os países não acontece de forma igualitária, conforme apontam os estudos de Tundisi (2003) e Rebouças (2003), o que leva a incidência de uma crise hídrica em vários países.

O Brasil é um dos países mais ricos em água doce do planeta, sendo assim, apresenta uma situação privilegiada em termos de recursos hídricos. Porém, a distribuição de água doce não acontece de forma igual, seja pela localização geográfica ou pela demanda de água para atender a população.

Os usos múltiplos e inadequados interferem na qualidade da água em diferentes escalas e acarretam a diminuição da sua quantidade em termos de qualidade. Além de ser um recurso limitado e dotado de valor econômico, conforme Política Nacional de Recursos Hídricos (BRASIL, 1997), ela é também um bem de domínio público e, assim sendo, todos tem o direito ao seu uso.

A importância da água faz com que hoje ela seja uma preocupação mundial diante das ameaças da poluição, do uso insustentável, das mudanças climáticas, das mudanças no uso do solo e do risco de escassez.

Diante deste contexto, tem-se como questionamento principal como a Educação Ambiental pode auxiliar a conservação, preservação e recuperação de recursos hídricos?

Quando se pensa sob a ótica civilizacional, para permitir à água a qualidade do seu ciclo, há necessidade de investimento num modelo de educação que não aparte o homem da natureza, propiciando que a visão antropocêntrica ceda lugar para uma consciência planetária.

Portanto, abordar o elemento água como uma necessidade vital requer uma educação humana que torne evidente todos os componentes naturais, técnicos, sociais, culturais, éticos e políticos que influenciam a tomada de decisão na questão do acesso, quantidade e qualidade da água.

O papel do professor é de suma importância ao contribuir para a formação dos alunos com práticas educativas voltadas à compreensão da realidade local e global e o fomento de hábitos e atitudes, no que diz respeito ao uso racional da água.

É fundamental que a abordagem do uso múltiplo da água e os problemas que envolvem os recursos hídricos locais possam ser sustentados na Educação Ambiental, a qual potencialmente deve ser um instrumento de alteração de padrões de comportamento e de valorização do meio ambiente.

No Município de Tenente Portela-RS, está sendo desenvolvido o Projeto Piloto Guardiões das Águas Mirins tendo como foco as crianças e jovens da zona rural do Município. O Projeto Piloto visa a implementação de ações de cunho socioambiental, que contribuirão na execução da política municipal do meio ambiente e de recursos hídricos, a implantação de seus princípios e instrumentos, através da conservação, preservação e recuperação dos recursos hídricos.

Para que fossem atendidos os objetivos da pesquisa tornou-se necessário proceder a um levantamento e revisão bibliográfica teórico-conceitual, para apoiar os estudos sistematizados dos conceitos necessários ao estudo.

A pesquisa está estruturada, conforme descrição a seguir:

Educação Ambiental - é discutido o conceito de Educação Ambiental, sua eficácia na promoção da participação e da cidadania e a sua importância na gestão dos recursos hídricos.

O recurso natural: a água - é abordada a água como um elemento da natureza, descrevendo as características estruturais, a sua importância para vida e apresenta discussões a respeito de sua disponibilidade, distribuição e usos. É abordada a dimensão ambiental dos recursos hídricos e a gestão dos recursos no Brasil. 
Guardiões das Águas: Iniciativa municipal de Educação Ambiental - descreve o exemplo das ações em Educação Ambiental que favorece a participação da comunidade na preservação, conservação e recuperação dos recursos hídricos.

Finalmente, são apresentadas a análise dos resultados do Projeto Piloto Guardiões das Águas Mirins, as conclusões e recomendações desta pesquisa.

\section{Metodologia}

A pesquisa-ação é definida, por Thiollent (2005), como uma metodologia derivada da pesquisa social com base empírica, concebida e realizada em estreita associação com uma ação ou a resolução de um problema coletivo, e na qual pesquisadores e participantes representativos da situação ou problema estão envolvidos de modo cooperativo ou participativo.

Sato (1997) considera essa metodologia a mais indicada para pesquisas em Educação Ambiental por permitir a participação dos envolvidos por meio de reflexões críticas de um problema percebido por todos, potencializando a emancipação e a participação social. A autora destaca ainda que a pesquisa-ação está sendo amplamente difundida e utilizada nos grandes projetos realizados em diversos países europeus onde professores são estimulados a desenvolver atividades em Educação Ambiental nas suas escolas.

De acordo com Tozoni-Reis (2005), a metodologia de pesquisa-ação em Educação Ambiental está centrada em três "práticas" que se articulam entre si: a produção de conhecimento, ação educativa e a participação dos envolvidos, tomando, como ponto de partida, um problema existente e detectado pelas equipes. Nesta pesquisa, os participantes deixam de ser objeto de estudos para serem pesquisadores e produtores de conhecimento de sua própria realidade.

A pesquisa-ação tem, como característica principal, a construção coletiva do conhecimento, onde todos têm voz ativa (GONZALES, TOZONI-REIS e DINIZ, 2007).

De acordo com a fundamentação teórica da pesquisa-ação, o público alvo desta pesquisa foram os alunos participantes do Projeto Piloto Guardiões das Águas Mirins do município de Tenente Portela - RS e o acompanhamento das ações desenvolvidas pelo Projeto. Estabeleceu-se as seguintes etapas metodológicas para esta pesquisa: escolha da escola, sensibilização do corpo docente e discente, a seleção da área de implantação do Projeto, elaboração do plano de recuperação da mata ciliar, execução do plano de recuperação da mata ciliar e a mobilização da comunidade escolar e expansão do Projeto Piloto.

\section{Resultados e Discussão}

\subsection{Escolha da escola}

O município de Tenente Portela - RS apresenta uma área territorial de $341,6 \mathrm{~km}^{2}$, divididos em zona urbana, rural e Reserva Indígena do Guarita.

Considerando os fatores da área rural do Município ser formada por propriedades de até 20 hectares, de a economia estar baseada na produção de grãos, leite e criação de suínos e aves, apresentar oito escolas localizadas na zona rural e da presença de considerável número de nascentes e cursos d'água no Município, os critérios de escolha da escola foram:

- localização na zona rural do município de Tenente Portela - RS;

- corpo discente composto por filhos de agricultores;

- a escola já estar engajada em projetos socioambientais;

- ter na área de abrangência da comunidade escolar nascentes ou cursos d'água;

- exploração do solo por cultivo de monoculturas.

A escola que atendeu os requisitos de escolha foi a Escola Estadual de Ensino Fundamental General Osório, localizada no Distrito de São Pedro. O Educandário possui 86 
alunos matriculados, distribuídos em Educação Infantil e Educação Básica, 12 professores e 06 funcionários.

Acredita-se que a Escola seja o espaço público e democrático que resgata saberes, produz conhecimentos e desenvolve potencialidades para o futuro. Espaço onde ocorrem mudanças de mentalidades, de comportamentos e de práticas, fatores imprescindíveis para a sensibilização dos sujeitos e para a promoção do desenvolvimento local (NEFA; SILVA; CERQUEIRA, 2011).

$\mathrm{Na}$ Escola General Osório evidencia-se experiências bem sucedidas haja vista que todos (alunos, professores, funcionários e pais) estão comprometidos com a Educação Ambiental.

A Escola adotou uma metodologia baseada em projetos com o objetivo de discutir informações sobre o Meio Ambiente com seu público estudantil. Essa metodologia visava o desenvolvimento de ações que contemplassem a Educação Ambiental Transformadora, que deve ser entendida enquanto transformadora social à medida que desenvolve atitudes e valores necessários para a modificação da atual situação de devastação do planeta. Destaca-se como ações do Educandário:

A construção da Escola primou pela manutenção e conservação de uma área verde, formada por exemplares arbóreos nativos. A área verde está dentro dos limites da Escola e tornou-se uma sala de aula ao ar livre, permitindo aos alunos a prática de uma relação mais harmônica entre o homem e a natureza.

Diante disso, foi efetuado o florestamento das margens da estrada que dá acesso a Escola e também do campo esportivo da comunidade. Inicialmente foi realizado um levantamento das espécies que formavam a área verde e depois efetuado o plantio de mudas. Todas as árvores foram identificadas e estão catalogadas no acervo da Escola.

É extremamente importante que os alunos se conscientizem e tenham ações práticas que reduzam o seu impacto sobre o planeta Terra, exemplo disso é a prática da separação dos resíduos e adoção dos 5Rs (repensar, reduzir, recusar, reutilizar e reciclar) adotada na Escola. O lixo orgânico é destinado para compostagem e posterior a esse processo o adubo é utilizado no cultivo da horta.

O cultivo da horta permite que os alunos resgatem os valores culturais e aprendam técnicas de cultivo e épocas de plantio, contribuindo assim para que seja oferecida aos alunos uma alimentação saudável. O incentivo para o desenvolvimento de hortas domiciliares faz com que em casa o aluno também tenha acesso a alimentos de qualidade e sem adição de agrotóxicos, podendo representar um agregado na fonte de renda da família.

Outra iniciativa é a interação com o meio onde a Escola está inserida que se dá através de trilhas ecológicas organizadas com o objetivo de conhecer as áreas que formam a comunidade escolar, os principais problemas encontrados e as formas de serem solucionados.

A respeito de Projetos desenvolvidos com ênfase na Educação Ambiental, os estudos de Tamaio (2002, p. 23) afirmam que:

Atualmente atribuem à Educação Ambiental uma importância fundamental para a "obtenção de resultados" em favor da conservação e melhoria do meio ambiente. No entanto, diante de uma situação social complexa, a educação deve desempenhar um papel para favorecer o desenvolvimento de novos comportamentos individuais e coletivos que visem superar as condições históricas atuais.

Para Reigota (1994), na Educação Ambiental escolar deve-se enfatizar o estudo do meio ambiente onde vive o aluno, procurando levantar os principais problemas da comunidade, as contribuições da ciência, os conhecimentos necessários e as possibilidades concretas para a solução deles.

Ao pensar alternativas metodológicas em Educação Ambiental, não se pode esquecer que, em muitos casos o mais importante não é o conhecimento científico e/ou a resolução do problema técnico enfrentado, mas, sim, a forma como se relaciona com ele. Que tipo de conhecimento e de saberes são mobilizados nesta relação; que métodos didáticos, pedagógicos e 
metodológicos são empregados. É desta metodologia de abordagem que, em muitos casos, pode resultar uma relação mais ou menos ecológica na produção de conhecimento. Sim, porque não basta produzir conhecimento científico e transformá-lo em tecnologias e artefatos técnicos. Há que se estar, também atentos para refletir e decidir quais tipos de conhecimento e de ciência se quer priorizar (BARCELOS, 2010).

Acolhendo as ações de Educação Ambiental desenvolvidas pela Escola foi implantando o Projeto Piloto Guardiões das Águas Mirins, visando sensibilizar e conscientizar as crianças e jovens (alunos) sobre a importância de preservar e recuperar os recursos hídricos.

\subsection{Sensibilização do corpo docente e discente}

A proposta de implantação do Projeto Piloto Guardiões das Águas Mirins inicialmente foi apresentada a direção, professores e funcionários da Escola. $\mathrm{Na}$ apresentação foram destacados os objetivos, metodologia, desenvolvimento, execução e avaliação do Projeto.

A reunião inicial permitiu conhecer como os professores das diferentes áreas do conhecimento vinham trabalhando a EA; quais eram suas dificuldades e quais eram as vantagens do trabalho interdisciplinar; o que pensavam sobre o Projeto e quais eram suas expectativas diante daquela proposta de trabalho.

Baseando-se nas informações dadas pelos professores, a equipe técnica e a pesquisadora, obtiveram subsídios para fundamentar os próximos encontros de formação de multiplicadores de Educação Ambiental.

$\mathrm{Na}$ dimensão interdisciplinar, as diversas disciplinas contribuem para abordagens conceituais consistentes, abrangentes e atualizadas dos fenômenos relativos a uma área específica de atuação, embora sem perderem suas identidades enquanto conjuntos orgânicos de conhecimentos. (SOUZA, 1996, p. 16).

Dando continuidade, o segundo encontro de formação baseou-se no proposto por Medina (1999), e teve como objetivo a criação de subsídios teóricos e metodológicos aos técnicos em Educação para a orientação da elaboração da inserção curricular de Educação Ambiental, propiciando aos participantes condições técnicas e metodológicas de se construir uma matriz de problemas sócio-ambientais da localidade, com o intuito de promover a inserção transversal dos conteúdos/atividades da Educação Ambiental e desenvolvendo junto aos participantes habilidades de percepção ambiental e sensibilização para a análise crítica da realidade ambiental global, nacional, estadual e local. Também foi elaborado, coletivamente e de modo participativo, o cronograma das atividades que seriam realizadas com os alunos. "A metodologia mais apropriada da EA é a participação do sujeito no processo educativo. A participação é um processo que gera a interação entre diferentes atores sociais na definição do espaço comum e do destino coletivo (LOUREIRO, 2004, p.71)".

A partir da sensibilização do corpo docente considerou-se que a abordagem discente deveria ocorrer através da separação por anos de aprendizagem a fim de desenvolver atividades condizentes com a faixa etária.

Inicialmente, trabalhou-se a importância da socialização, o senso de cooperação e de solidariedade, através de dinâmicas de grupo e atividades recreativas. Esta fase foi muito importante, pois permitiu estreitar os laços entre os alunos, assim estando mais próximos faz com que o grupo se ajude mutuamente e desenvolva maior confiança.

Com os alunos mais entrosados, o próximo passo foi despertar a atenção dos educandos para o tema central do Projeto que é a água.

Os professores de forma interdisciplinar desenvolveram atividades variadas: dicas, informativos, análise de gravuras, reportagens escritas e televisivas, filmes educativos, estudos de casos, pesquisas e debates.

$\mathrm{Na}$ sala de aula, os professores priorizaram o tipo de abordagem comunicativa, interativa e dialógica. As aulas expositivas, realizadas pelos professores, tiveram como finalidade introduzir 
os assuntos novos, realizar sínteses, manter o rumo dos objetivos da Educação Ambiental. As ideias eram exploradas pelos professores e estudantes conjuntamente e os diferentes pontos de vistas eram discutidos e avaliados.

A interdisciplinaridade, como princípio e atitude, constitui foco de discussão para pesquisadores e educadores de vários níveis de ensino, que, ao reconhecerem a complexidade do mundo pós-industrial e o processo de globalização, vivenciados pelos povos do mundo inteiro, estão cientes de que os saberes parcelares não dão conta de resolver problemas que demandam conhecimentos específicos, relacionados a um objetivo comum e central. (PONTUSCHKA et al., 2007).

Aproveitando a socialização das atividades, a equipe técnica do Departamento Municipal de Meio Ambiente, responsável pela elaboração do Projeto Piloto Guardiões das Águas Mirins, realizou a apresentação dos objetivos, da implantação e execução do Projeto aos educandos.

Diante dos trabalhos teóricos e bibliográficos desenvolvidos, foi realizada uma trilha ecológica supervisionada a um recurso hídrico previamente selecionado pela equipe técnica e professores da Escola. Da nascente a foz do curso d'água, pode-se observar os impactos ocasionados pela prática de atividades predatórias na natureza. A oportunidade foi considerada como uma enriquecedora troca de conhecimentos entre os atores envolvidos.

\subsection{Seleção da área de implantação do projeto}

O Distrito de São Pedro é formado por aproximadamente 600 habitantes. As principais atividades agrícolas desenvolvidas na localidade são o cultivo de monoculturas de soja, milho, fumo e a criação de suínos em sistema de terminação.

Em estudo realizado por Ananias (2012), a autora descreve que "com relação às águas é pertinente adotar uma metodologia que considere o contexto vivido. É relevante investigar os mananciais que abastecem o local de moradia, os usos da água no cotidiano, se ocorre ou não poluição das águas, as formas de tratamento e distribuição da água potável, se o saneamento básico é disponível para a população, bem como problematizar o desperdício e promover ações na escola e nas residências para economizar a água, ampliando as atividades que possuem como base o tema água e a Educação Ambiental".

Baseado na descrição do estudo da autora, foi proposto o levantamento e análise da hidrologia do Distrito, fossem eles nascentes ou cursos d'água, e a situação de preservação das matas ciliares.

A integração da realidade socioambiental dos alunos com o conteúdo curricular fortalece o processo de formação da habilidade de transferência de conhecimento, que é um dos maiores objetivos da Educação (BASILE, 2000).

Inicialmente o levantamento foi realizado através de informações coletadas com os alunos que estudam na Escola General Osório. O levantamento com proprietários de terras que não possuem vínculo com a Escola foi realizado pela equipe técnica com a colaboração da pesquisadora.

A partir do levantamento dos recursos hídricos, constatou-se que a maioria dos casos havia ação antrópica, que resultaram na remoção da mata ciliar para criação de animais ou plantio de culturas.

Frade, Pozza e Borém (2010) afirmam ainda que a Educação Ambiental empregada nas escolas, por exemplo, deve possuir uma visão crítica e, para tanto, é necessário que sejam discutidas as degradações ambientais de maneira integrada em todos os campos do saber.

Os dados obtidos nos levantamentos fundamentaram o estudo e a análise da ocupação do solo no Distrito, formas de exploração dos recursos hídricos, atividades poluidoras e ações de preservação dos recursos naturais na propriedade dos educandos.

Nas próximas ações, os alunos dos anos iniciais puderam expor a realidade da propriedade em que vivem através de desenhos e colagens de gravuras; os discentes dos anos finais descreveram e debateram as situações vivenciadas na propriedade. 
A avaliação dos dados pelos alunos da Escola General Osório, supervisionados pelos professores, equipe técnica e pesquisadora concluíram que a área para a implantação do Projeto Piloto deveria ser uma nascente localizada na propriedade do senhor Ari José Tirloni.

A nascente selecionada é um afloramento do lençol freático que vai dar origem a um curso d'água de $2 \mathrm{~km}$ de extensão. A nascente é classificada como fluxo de água contínuo, difusa e degradada.

Segundo Lima e Zakia (2000), porém, antes da aplicação da prática da educação e recuperação ambiental, é necessário avaliar quais são as experiências acumuladas sobre temas referentes à recuperação de matas ciliares e de educação ambiental ligadas diretamente à problemática dos agricultores. Para os agricultores, a presença da mata ciliar pode ser um problema, pois representa um obstáculo ao livre acesso do gado à água.

Dessa maneira, foram realizadas visitas a área selecionada, primeiramente para conhecer as experiências do proprietário em relação ao uso dos recursos naturais e a preservação dos mesmos. Nesta oportunidade, foi apresentada ao proprietário a proposta de implantação do Projeto que inclui a recuperação da área. $\mathrm{O}$ consentimento do proprietário foi dado através da assinatura do termo: de Compromisso ao Programa Guardiões das Águas, constante no Anexo B. Após o consentimento do proprietário, o local foi nomeado pelos alunos de Nascente Nono Tirloni.

Deste modo, a educação escolar passa a fazer parte do movimento emancipatório de caráter popular articulado com as lutas da comunidade organizada, assumindo, nas gerações futuras, o caráter de intervenção sobre a realidade, e não permanecendo na simples constatação de fatos. (SAITO, 1999).

Segundo Marodin, Barba e Morais (2004), a Educação Ambiental visa o desenvolvimento sustentável, ou seja, busca mudar hábitos enraizados na sociedade para possibilitar que as gerações futuras também possam fazer uso dos recursos naturais disponíveis atualmente.

\subsection{Elaboração do plano de recuperação ambiental da mata ciliar}

O segundo passo foi realizado em outra visita e constituiu na avaliação ambiental da área a fim de se obter informações e reconhecer os indicadores ambientais da degradação em questão: pisoteio do gado que utiliza o local para dessedentação, solo compactado, dejetos de gado e assoreamento. Um ponto positivo era que o local ainda preservava alguns fragmentos de mata ciliar que serviram de reserva à biodiversidade local.

Segundo Zanzarine e Roselen (2007) o pisoteio do gado, caracterizados por marcas das patas, indicavam que estes se dessedentavam na nascente causando assoreamento e comprometendo a qualidade da água e a vazão. O agravamento deste quadro é a ausência da mata ciliar, pois, um de seus importantes papéis, é a interceptação de sedimentos. Sua ausência no local não filtrou os sedimentos e provocou assoreamento. Também sua ausência influenciou na diminuição da presença da fauna local que buscava abrigo e alimento. Todos estes elementos são necessários à manutenção da qualidade ambiental. O solo compactado demonstra a intensidade com que o gado se desloca pelo local, um solo compactado tem sua infiltração comprometida. O material orgânico, dejetos do gado, contribuiu para o aumento da matéria orgânica no solo, o que pode tornar o solo mais fértil, mas o excesso desse material contribui para a contaminação tanto do solo quanto da água, pois, com a compactação do solo e a ausência da mata ciliar, parte destes dejetos escoa para o rio, comprometendo a qualidade de água, elevando também o nível de DBO (demanda bioquímica de oxigênio) e a concentração de fósforo, podendo provocar a eutrofização das águas e o comprometimento da vida aquática e do consumo dessa água.

Avaliados e constatados os indicadores de degradação ambiental, foi possível traçar o Plano de Recuperação Ambiental.

Na elaboração do Plano de Recuperação Ambiental da Mata Ciliar foram consideradas as variáveis culturais e sociais presentes e teve por objetivos gerar benefícios para todo o ambiente natural, assim como para o social, estando calçado no processo participativo e com forte componente de educação ambiental. 
A pesquisa para elaboração do Plano foi iniciada com um trabalho de campo, os alunos interagiram com o proprietário participando ativamente. A principal atividade na elaboração do Plano se dá pela observação.

Através da percepção da existência de glebas de áreas nativas próximas da nascente foi possível diagnosticar um estoque de reservas a fim de recompor a área em questão. A identificação das espécies foi realizada através de troca de conhecimentos entre o proprietário, equipe técnica, pesquisadora e alunos.

A possibilidade de uma recuperação mais rápida pode ser propiciada pela incorporação de espécies nativas. Sobre esse plantio Botelho e Davide (2007, pg. 23), descrevem que "devem ser nativas das matas ciliares da região do plantio, pois são as mais adequadas para o ambiente e terão maiores chances de crescer e se reproduzir, garantindo a recuperação da mata".

No entorno da nascente, os principais pontos a serem considerados foram a proximidade com a residência e postes de fiação de alta tensão e representaram os fatores limites da área a ser recuperada e tipos de exemplares a serem plantados.

Os itens definidos no Plano de Recuperação Ambiental da Mata Ciliar foram: isolamento da área, o levantamento prévio da vegetação existente, tipo de espécies a serem plantadas, número de mudas, disposição e plantio das mudas, época de plantio e tratos culturais.

\subsection{Execução do plano de recuperação ambiental da mata ciliar}

A execução do Plano de Recuperação Ambiental da Mata Ciliar foi compartilhada entre o proprietário da área, alunos e professores da Escola General Osório, equipe técnica do Departamento Municipal de Meio Ambiente e pesquisadora, respeitando as referências metodológicas descritas no referido Plano.

O primeiro passo tomado nas medidas de recuperação foi o isolamento da área através do cercamento, o qual foi realizado com arame farpado dispostos em três linhas redirecionados por mourões em madeiras fixados nos solos. Esta metodologia foi proposta para mitigar os agentes degradadores.

O pasto e os animais devem ser afastados, ao máximo, da nascente, pois, mesmo que os animais não tenham livre acesso à água, seus dejetos contaminam o terreno e, nos períodos de chuvas, acabam por contaminar a água. Essa contaminação pode provocar o aumento da matéria orgânica na água, o que acarretaria o desenvolvimento exagerado de algas bem como a contaminação por organismos patogênicos que infestam os animais (CALHEIROS, 2004).

A questão a ser ressaltada foi o fato de que o cercamento, respeitando a largura de 50 metros como determina a legislação ambiental, não foi autorizado. Ocorreram discussões sobre a necessidade de se cumprir à legislação e, consequentemente, de se recuperar tal área. A autorização veio por um acordo adequando a área cercada em 20 metros de raio.

Através da percepção da existência de glebas de áreas nativas próximas à área recuperada, foi possível diagnosticar um estoque de reservas a fim de recompor a área em questão. A possibilidade de uma recuperação mais rápida pode ser propiciada pela incorporação de espécies nativas.

Sobre esse plantio Kageyama (2000) justifica o uso de espécies nativas em programas de recuperação ambiental pelas mesmas terem evoluído no local, tendo, portanto, mais chances de aí encontrarem seus polinizadores, dispersores de sementes e predadores naturais, mantendo assim a capacidade de reprodução e regeneração natural das populações.

Considerando o clima e o tipo de solo, fatores preponderantes, e outros provenientes do trabalho de campo - maior ocorrência na mata ciliar remanescente, foi selecionada nove espécies de plantas nativas: Psidium cattleyanum Sabine (araçá vermelho), Sebastiania Commersoniana (branquilho), Matayba Guyanensis. (camboatá branco), Myrciaria tenella (camboim), Casearia Silvestris (chá de bugre), Allophylus edulis (chal chal), C. pubescens var. coarectatum O. Berg 
(guabiroba), Prunus myrtifolia (L.) Urb. (pessegueiro bravo) e Eugenia uniflora (pitanga) para o reflorestamento da mata ciliar.

Antes do plantio, procedeu-se ao combate às formigas cortadeiras em toda a área, bem como numa faixa de 100 metros de largura em volta da área.

As covas possuíam aproximadamente $40 \mathrm{~cm}$ de diâmetro e $50 \mathrm{~cm}$ de profundidade, onde foi incorporado adubo orgânico e o plantio de 250 mudas. Houve o coroamento das mudas num raio aproximado de $25 \mathrm{~cm}$ da muda. O espaçamento foi adequado de acordo com as medidas do terreno, com um intervalo de aproximadamente 2 metros entre elas.

Em relação aos tratos culturais, foi efetuada a limpeza da área, preferencialmente, a vegetação herbácea e da subarbustiva invasora, que poderiam competir com as mudas das espécies arbóreas em busca de luz, de umidade e de nutrientes. A matéria vegetal morta, resultante da limpeza, foi mantida na área, formando uma manta protetora do solo, que serviu também como fonte de nutrientes e de matéria orgânica.

O replantio será efetuado no período de agosto a setembro do ano subseqüente, se a taxa de sobrevivência em campo for inferior a $80 \%$.

\subsection{Mobilização da comunidade e expansão do Projeto Piloto}

A mobilização das comunidades, por meio da realização de eventos que fortalecem seus vínculos com os cursos de água, pode ser uma forma bem efetiva de ampliar o envolvimento do público. (ANA, 2011).

Baseado nisso, o lançamento oficial do Projeto Piloto Guardiões das Águas Mirins foi realizado no Distrito de São Pedro, fazendo parte da programação da II Semana Municipal da Água, em consonância com as atividades desenvolvidas na XX Semana Interamericana da Água e a XIII Semana Estadual da Água, que este ano teve como tema "Cuidar do arroio é proteger a água".

O evento foi aberto a todos os munícipes da zona urbana e rural de Tenente Portela - RS, Escolas Municipais e Estaduais, associações de agricultores, cooperativas, sindicatos, autoridades executivas e legislativas, instituições financeiras e imprensa.

$\mathrm{Na}$ oportunidade, houve a apresentação dos resultados alcançados através da parceria firmada entre o Departamento Municipal de Meio Ambiente, Escola Estadual de Ensino Fundamental General Osório e produtor rural Ari José Tirloni no desenvolvimento do Projeto Piloto Guardiões das Águas Mirins.

$\mathrm{Na}$ avaliação da equipe técnica do Departamento de Meio Ambiente, a adesão dos atores sociais (alunos, professores, funcionários e família do senhor Ari José Tirloni) nas atividades propostas no Projeto Piloto representaram a chave para que os objetivos fossem alcançados. A integração entre a educação ambiental formal e informal permitiu que o tema central do Projeto, a água, contemplasse a totalidade e representou a possibilidade de motivar e sensibilizar as pessoas para transformar as diversas formas de participação na defesa da qualidade de vida.

O desenvolvimento de uma consciência ambientalista, muito mais do que medidas punitivas, ainda é o meio mais eficaz de diminuir esse grande problema da água. As gerações atuais precisam de uma nova cultura em relação ao uso da água, pois, além da garantia de seu próprio bem-estar e sobrevivência, devem cultivar a preocupação com as próximas gerações e com a natureza, as quais também têm direito a esse legado (MORAES; JORDÃO, 2002).

A participação e o depoimento da família do senhor Ari José Tirloni no evento foi de grande valia. A família relatou a experiência na prática da agricultura extensiva e exploratória que foi a garantia de fonte de renda por muitos anos e como a diminuição da disponibilidade hídrica na propriedade fez com que a atividade predatória exercida fosse substituída por ações de preservação. A adesão ao Projeto Piloto foi relatada como positiva e uma forma de assumir a responsabilidade na recuperação dos danos causados e conservação do bem natural que poderá voltar a ser abundante na propriedade. 
Como forma de reconhecimento pelo trabalho e empenho no cumprimento das ações previstas pelo Projeto Piloto e no Plano de Recuperação Ambiental da Mata Ciliar, a família recebeu o certificado de honra ao mérito pelo bem prestado ao meio ambiente.

Essa participação tem o seu fundamento no art. 225, da Constituição Federal 1988 que, ao tratar do Meio Ambiente, impõe ao Poder Público e à coletividade o dever de defendê-lo e preservá-lo para as presentes e futuras gerações (BRASIL, 1988). Por esse princípio, a sociedade, como um todo, tem direito de manifestar a sua opinião e o seu referendo sobre a proteção ao meio ambiente, podendo exigir esta proteção como um exercício de legitimação da cidadania e da dignidade humana. (THOMAS, 2010).

O Ministério do Meio Ambiente orienta que o objetivo geral da Educação Ambiental é formar cidadãos ativos que saibam identificar os problemas e participar efetivamente de sua solução e prevenção (MELO,2007). A consciência ambiental é formada mediante o conhecimento do meio ambiente. Esse conhecimento impulsiona as pessoas a tomar atitudes e desenvolver habilidades para resolver seus problemas ambientais e exigir do Estado políticas públicas que amenizem os impactos criados pelos novos processos de desenvolvimento. Portanto, é necessária a participação ativa da população nas questões ambientais. A participação no processo da educação ambiental deve ser permanente, cotidiana e coletiva, que transforme a realidade da vida baseada nos caminhos democráticos, sustentáveis e justos para todos (LOUREIRO, 2004).

A participação no Projeto Piloto Guardiões das Águas Mirins foi considerada pela Direção da Escola General Osório como uma renovação das atividades de educação ambiental exercidas pelo educandário. A diretora pontuou que, considerando que as ações foram desenvolvidas na Escola e com a comunidade escolar, permitiu a promoção da visibilidade do Projeto e despertou o interesse de mais pessoas.

No depoimento dos discentes, foi destacado como pontos positivos a aproximação entre a teoria e o cotidiano dos alunos, a participação no levantamento dos recursos hídricos da localidade, a visita a área selecionada, a elaboração conjunta do Plano de Recuperação e a execução do Plano (cercamento da área e plantio das mudas).

Através do depoimento, pôde-se perceber que tendo o aluno como sujeito da ação a repercussão foi positiva, assim formou-se o conhecimento a partir da vivência e da observação como sendo fundamental na prática da Educação Ambiental.

$\mathrm{Na}$ comparação dos resultados obtidos durante a realização da pesquisa com aqueles encontrados por Silva (2007), pode-se concluir que a Educação Ambiental no ensino fundamental é importante, mas deve ser conduzida de uma forma mais prática promovendo a capacidade do aluno de compreensão de que mudanças são necessárias na sociedade atual para que a degradação ambiental diminua, que ele próprio é parte integrante deste meio, e que todos podem trabalhar para que as mudanças necessárias ocorram aumentando a qualidade de vida de todos.

Os alunos aproveitaram a oportunidade para apresentação de uma paródia e uma peça teatral, escritas baseadas nas experiências adquiridas com o Projeto Piloto. A apresentação surpreendeu a plateia pela qualidade do enredo e desenvoltura dos alunos.

A equipe técnica homenageou os alunos, professores e funcionários da Escola General Osório entregando a eles um certificado de "Guardiões das Águas" pela participação e colaboração no desenvolvimento do Projeto Piloto.

\footnotetext{
A participação dos diversos atores sociais se apresentam como aspecto fundamental para obter resultados positivos, assim como positiva seria a sinergia entre a ampliação dos horizontes de participação política dos segmentos menos favorecidos da sociedade e a luta pelos demais direitos socioculturais associados, permitindo uma compreensão mais integrada da promoção da cidadania de indivíduos e grupos inteiros atualmente apartados. (VARGAS et al, 2004, p. 235).
}

Como estratégia para efetivação da participação do público do Evento, composto por representantes da sociedade, a pesquisadora conduziu os trabalhos. Primeiramente, os participantes foram divididos em grupos. A proposta apresentada aos grupos era que fosse 
elencada, de acordo com a realidade vivenciada, a situação dos recursos hídricos e medidas de recuperação e conservação desse bem natural.

A socialização da atividade permitiu uma troca de experiências enriquecedoras e culminou na manifestação do interesse de cinco proprietários do Distrito de São Pedro em aderir ao Programa Guardiões das Águas.

Diante do exposto, as próximas ações incluem a elaboração e execução de Planos de Recuperação dessas novas áreas e implantação do Programa em outras localidades do interior do Município. Em relação ao Projeto Piloto, o mesmo será implantando no próximo ano na escola municipal do Distrito de Daltro Filho.

A disseminação das informações sobre o Projeto foi intensificado através do serviço de rádio local e dos jornais impressos.

A Educação Ambiental deve ser uma concepção totalizadora de Educação e que é constatada quando é originada de um projeto que englobe a escola, a comunidade e os movimentos populares organizados comprometidos com a preservação da vida em seu sentido mais profundo. (GUIMAR ̃̂ES, 2007).

\section{Conclusão}

A realização do estudo Guardiões das Águas Mirins: integrando experiências de preservação de recursos hídricos e Educação Ambiental proporcionou o conhecimento de como as ações e práticas de conservação, preservação e recuperação dos recursos hídricos são conduzidas na escola através do Projeto Piloto Guardiões das Águas Mirins.

Em conformidade com os objetivos pretendidos e os resultados auferidos com este estudo, pode-se concluir que:

- Auxílio no levantamento quantitativo das nascentes, fontes e cursos d' água na área de abrangência da comunidade escolar da zona rural.

O levantamento dos recursos hídricos (nascentes e cursos d'água) foi realizado através de informações coletadas com os alunos da Escola Estadual de Ensino Fundamental General Osório e nas outras propriedades da comunidade escolar através de visita realizada pela equipe técnica e pesquisadora. ambientais.

- Realização de visitas na área selecionada com os alunos para avaliação dos indicadores

A nascente nomeada pelos alunos como Nascente Nono Tirloni foi a área selecionada para recuperação da mata ciliar.

De modo geral, pode-se considerar que as visitas supervisionadas na área selecionada foram fundamentais para o desenvolvimento da percepção ambiental dos alunos. Extrapolar o espaço interior da sala de aula e privilegiar o espaço exterior na busca do conhecimento e das experiências ambientais representou uma ação positiva.

Com a experiência os alunos puderam observar e identificar o tipo de vegetação remanescente e reconhecer os indicadores ambientais da degradação: pisoteio do gado que utiliza o local para dessedentação, solo compactado, dejetos de gado e assoreamento.

- Participação com os alunos da elaboração do Plano de Recuperação Ambiental da Mata Ciliar da área selecionada.

A elaboração do Plano de Recuperação Ambiental da Mata Ciliar contou com a participação dos alunos da Escola General Osório, proprietário da área selecionada, equipe técnica do Departamento Municipal de Meio Ambiente e pesquisadora.

O engajamento do proprietário rural na elaboração foi uma estratégia funcional para incentivar a adesão às iniciativas de conservação ambiental e a participação dos alunos foi um exercício de cooperação na busca das soluções do problema proposto, discutindo as razões para optar por um ou outro encaminhamento, explorando as conexões entre teoria e experiência.

Em suma, trata-se de agir e refletir coletivamente, buscando um aprimoramento da ação.

- Apoio ao desenvolvimento de ações de comunicação e educação junto a população e mobilização social. 
No que diz respeito à divulgação, a apresentação das ações do Projeto aconteceu no evento promovido na II Semana Municipal da Água, e fez parte do calendário de divulgação da XIII Semana Estadual da Água.

O processo de sensibilização, consciência, conhecimento e mobilização da comunidade são contínuos sendo realizados seminários, palestras e visitas a campo em propriedades que participam de Programa. Desse modo, a Educação Ambiental ganha enorme destaque devido à sua capacidade de conciliar conhecimento, engajamento e mudanças de hábitos e atitudes.

Concluímos que o desafio de promover a Educação Ambiental de qualidade, crítica, transformadora no ambiente escolar foi alcançado, ficando evidente na mudança de atitude dos alunos em relação ao consumo da água no ambiente escolar e em seu contexto familiar e a tomada de consciência sobre o tema água, bem como da importância da preservação desse recurso para a qualidade de vida. Nesse contexto, destaca-se que docentes comprometidos e com formação adequada sobre água colaboram para a construção de espaços formativos e na educação de indivíduos mais preocupados com as questões ambientais, o que possibilita novos caminhos para o futuro da sociedade.

Além disso, acreditamos que investimentos para estabelecer parcerias entre a Rede Estadual e Municipal de Ensino e órgãos competentes vinculados a questão da água, como por exemplo, a Companhia Riograndense de Saneamento (CORSAN), o Comitê de Bacia Hidrográfica dos rios Turvo - Santa Rosa - Santo Cristo/RS, Organizações NãoGovernamentais, Secretaria Estadual do Meio Ambiente, Departamento Municipal de Meio Ambiente são oportunos no sentido de qualificar o trabalho realizado sobre Educação Ambiental, especificamente sobre o tema água.

Por fim encerra-se, com explicitado por Reigota (2004, pg.19) "problemas ambientais foram criados por homens e mulheres e deles virão as soluções. Estas não serão obras de gênios, de políticos ou tecnocratas, mas sim de cidadãos e cidadãs".

\section{Referências}

AGÊNCIA NACIONAL DE ÁGUAS (ANA). Cuidando das águas: soluções para melhorar a qualidade dos recursos hídricos / Agência Nacional de Águas. Programa das Nações Unidas para o Meio Ambiente. Brasília: ANA, 2011.

AGÊNCIA NACIONAL DE ÁGUAS - ANA. Lei no 9.984/00. Criação da Agência Nacional de Águas. Disponível em: <www.planalto.gov.br/ccivil_03/LEIS/L9984.htm>. Acesso em: 03 nov. 2013.

AGROANALYSIS. Lei $\mathrm{n}^{\circ}$ 9.433: Novo conceito das águas brasileiras. Agroanalysis, março, 1998.

ALMEIDA, Caroline Corrêa. Evolução histórica da proteção jurídica das águas no Brasil. 2002. Disponível em <http://jus.com.br/artigos/3421/evolucao-historica-da-protecaojuridica-das-aguas-no-brasil\#ixzz2kKyEvpBl> Acesso em: 30 set. 2013.

ALMEIDA, R.; REGIS, M. Águas sem barragens. Campanha Interestadual contra a Implantação de Barragens na Bacia Araguaia-Tocantins. São Luiz, 2002.

ANANIAS, Natália Teixeira. Educação Ambiental e Água: Concepções e Práticas Educativas em Escolas Municipais. Dissertação (mestrado) - Universidade Estadual Paulista, Faculdade de Ciências e Tecnologia, Presidente Prudente (SP), 2012. 
ARCOVA, F.C.S.; CESAR, S.F.; CICCO, V. Qualidade da água em microbacias recobertas por floresta de Mata Atlântica, Cunha, São Paulo. Revista do Instituto Florestal de São Paulo, São Paulo, v.10, n.2, p.185-96, 1998.

ARCOVA, F.C.S.; CICCO, V. Características do deflúvio de duas microbacias hidrográficas no laboratório de hidrologia florestal Walter Emmench, Cunha - SP. Revista do Instituto Florestal de São Paulo, São Paulo, v.9, n.2, p.153-70, 1997.

ARROYO, M. Educação e exclusão da cidadania. In: BUFFA, E. et al. Educação e cidadania: quem educa o cidadão?. São Paulo: Cortez, Polêmicas do Nosso Tempo, 1987.

BACCI, D.L.C; PATACCA, E.M.. Educação para a água. Estudos avançados, 2008.

BARCELOS, V. Educação Ambiental: Sobre princípios, metodologias e atitudes. Petrópolis,RJ: Vozes, 2010.

BASILE, C. G. Environmental education as a catalyst for transfer of learning in young children. The Journal of Environmental Education, v. 32, n. 1, p. 21-27, 2000.

BOTELHO, A. S.; e DAVIDE, A. C. Como Conservar e Recuperar Matas Ciliares. CEMIG, $2^{\text {a }}$ edição, 2007.

BRAGA, A. R. et al. Educação ambiental para gestão de recursos hídricos. Livro de Orientação ao Educador. Americana: Consórcio PCJ, 2003.

BRASIL. Constituição. Constituição da República Federativa do Brasil. 37. ed. São Paulo: Saraiva, 2005.

BRASIL. Lei ${ }^{0}$ 9.795, de 27 de Abril de 1999. Dispõe sobre a educação ambiental, institui a Política Nacional de Educação Ambiental e dá outras providências. Disponível em: <http://www.planalto.gov.br/ccivil/Leis/L9795.htm> Acesso em: 10 out. 2013.

BRASIL. Lei no 9.605/98 de 12 de fevereiro de 1998, Crimes Ambientais. Disponível em: <www.planalto.gov.br/ccivil/LEIS/L9605.htm>. Acesso em: 08 nov. 2013.

BRASIL, Lei $\mathrm{n}^{\circ}$ 9.433, de 8 de Janeiro de 1997. Institui a Política Nacional de Recursos Hídricos, cria o Sistema Nacional de Gerenciamento de Recursos Hídricos, regulamenta o inciso XIX do art. 21 da Constituição Federal, e altera o art. $1^{\circ}$ da Lei $n^{\circ}$ 8.001, de 13 de março de 1990, que modificou a Lei $\mathbf{n}^{\circ} 7.990$, de 28 de dezembro de 1989 . Disponível em: <http://www.planalto.gov.br/ccivil_03/LEIS/L9433.htm> Acesso em: 24 jun. 2009.

BRASIL. Lei $\mathrm{n}^{\mathbf{0}}$ 6.938/81 Política Nacional do Meio Ambiente. Disponível em: <www.planalto.gov.br/CCIVIL/LEIS/L6938.htm>. Acesso em: 08 de novembro de 2013

BRASIL. Lei $\mathbf{n}^{\circ} \mathbf{4 . 7 7 1 / 6 5}$ Código Florestal. Disponível em: <www.presidencia.gov.br/CCIVIL/leis/L4771.htm>. Acesso em: 08 nov. 2013

BRASIL. Decreto $\mathrm{n}^{\mathrm{o}}$ 24.643, de 10 de julho 1934. Decreta o Código de Águas. Disponível em: <http://www.planalto.gov.br/ccivil_03/decreto/d24643.htm> Acesso em: 24 out. 2013.

BRASIL, Ministério da Educação, Secretaria de Educação Continuada, Alfabetização e Diversidade. Processo Formador em educação ambiental à distância: módulo 3: mudanças ambientais globais. Brasília: MEC, 2009. 
BRASIL, Ministério da Saúde. Secretaria de Vigilância em Saúde. Coordenação-Geral de Vigilância em Saúde Ambiental. Programa Nacional de Vigilância em Saúde Ambiental relacionada a qualidade da água para consumo humano. Brasília: Editora do Ministério da Saúde, 2005.

BRASIL. Ministério da Saúde. Organização Pan-Americana da Saúde. Avaliação de impacto na saúde das ações de saneamento: marco conceitual e estratégia metodológica. Organização Pan-Americana de Saúde. Brasília: Ministério da Saúde, 2004.

BUSTOS, Myriam Ruth Lagos. A Educação Ambiental sob a ótica da Gestão de Recursos Hídricos. Tese (Doutorado) - Escola Politécnica da Universidade de São Paulo. Departamento de Engenharia Hidráulica e Sanitária. São Paulo, 2003.

CALHEIROS, R. de O. et al. Preservação e Recuperação das Nascentes - Piracicaba: Comitê das Bacias Hidrográficas dos Rios PCJ. Piracicaba: CTRN - Câmara Técnica de Conservação e Proteção aos Recursos Naturais, 2004.

CAMDESSUS, M.; BADRÉ, B.; CHÉRET, I. et al. Água: oito milhões de mortos por ano: um escândalo mundial. Rio de Janeiro: Bertrand, Brasil, 2005.

CAMPOS, J. D. Federalismo cooperativo e o princípio da subsidiariedade: notas sobre a experiência recente no Brasil e da Alemanha. In: Federalismo na Alemanha e no Brasil, Holmeister, W. e Carneiro, J.M.B.(orgs.). Fundação Konrad Adenauer, Série Debates n. 22, Vol.I, São Paulo, 2001.

CARVALHO, I.C.M.; SCHMIDT, L.C.. A pesquisa em educação ambiental: uma análise dos trabalhos apresentados na ANPED, ANPPAS e EPEA de 2001 a 2006. Pesquisa em Educação Ambiental, 2008.

CARVALHO, Isabel Cristina de Moura. Educação Ambiental: a formação do sujeito ecológico. São Paulo: Cortez, 2004.

CLARKE, Robin; KING, Jannet. O Atlas das Águas: Mapeamento Completo do recurso Mais precioso do Planeta. (Tradução: Ana Maria Quirino) Publifolha. São Paulo. 2005. CONSELHO NACIONAL DO MEIO AMBIENTE - CONAMA. Resolução no 20/1986. Disponível em: <www.mma.gov.br/port/conama/res/res86/res2086.html>. Acesso em $10 \mathrm{de}$ novembro de 2013.

DALLARI, Dalmo de Abreu. Direitos humanos e cidadania. 2. ed. São Paulo: Moderna, 2004.

DE FREITAS, Wladimir Passos. Águas: aspectos jurídicos e ambientais. 2 ed. Curitiba: Juruá, 2007.

DIAS, G. F. Educação ambiental, princípios e práticas. 9 ed. São Paulo: Gaia, 2004.

FERNANDES, Debora do Nascimento. A Importância da Educação Ambiental na Construção da Cidadania. Revista OKARA: Geografia em debate, v.4, n.1-2, p. 77-84, 2010.

FRADE. E. das G; POZZA, A. A. A; BORÉM, R.A.T. Educação Ambiental na diversidade: Guia de estudos. Lavras: UFLA, 2010.

FREITAS, V. P. Águas: Aspectos jurídicos e ambientais. 2ed. Curitiba: Juruá, 2003.

Fundação Nacional de Saúde (Funasa). Manual de saneamento. Brasília, DF, 1999. 
GADOTTI, Moacir. História das ideias pedagógicas. São Paulo: Ática, 1998.

GARRIDO, R. Considerações sobre a formação de preços para a cobrança pelo uso da água no Brasil. In: Thame, A. C. M. (Org.). A cobrança pelo uso da água. São Paulo: Igual, 2000 .

GEO Brasil. Ministério do Meio Ambiente; Agência Nacional de Águas; Programa das Nações Unidas para o Meio Ambiente. Recursos Hídricos: componente da série de relatórios sobre o estado e perspectivas do meio ambiente no Brasil. Brasília: MMA; ANA, 2007.

GONZALES, L. T. V.; TOZONI-REIS, M. F. C.; DINIZ, R. E. S. Educação ambiental na comunidade: uma proposta de pesquisa-ação. Revista Eletrônica Mestrado em Educação Ambiental, Rio Grande, v. 18, 2007. Disponível em <http://www.remea.furg.br/edicoes/vol18/art31v18a27.pdf>. Acesso em: 12 nov.2013.

GRANZIERA, M. L. M. Direito das águas e meio ambiente. São Paulo: Ícone, 1993.

GUERRANT, R L; SOUZA, M A; NATIONS, M K. At the edge of development: health crisis in a transitional society. Carolina Academic Press, 1996.

GUIMARÃES, M. Educação ambiental: no consenso um embate? $5^{\text {a }}$ ed. Campinas: Papirus, 2007.

HAVEN, P.H; BERG, L.R; JOHNSON, G.B. Environment. Saunders College Publishing, 1998.

JACOBI, Pedro. Educação Ambiental, cidadania e sustentabilidade. Cadernos de Pesquisa; $\mathrm{n}^{\circ} \quad 118 ; \quad$ p. 189-205; março/2003. Disponível em <www.scielo.br/br/pdf/cp/n118/16834.pdf>. Acesso em: 29 out. 2013. 2002.

JUNGSTEDT, L. C. Direito Ambiental: legislação. 2ed. Rio de Janeiro: Thex. Ed., KAGEYAMA, P.Y \& GANDARA, F.B. "Recuperação de Áreas Ciliares", In: Matas Ciliares: Conservação e Recuperação - São Paulo: EDUSP/FAPESP, 2000.

KIRA, T. e SAZANAMI, H.. Utilização de recursos hídricos e problemas de gerenciamento de lagos. In: HASHIMOTO, M. (ed.). Diretrizes para o gerenciamento de lagos. Japão. v. 2, 1995.

LAYRARGUES, Philippe Pomier. Para que a educação ambiental encontre a educação. In: LOUREIRO, Carlos Frederico B. Trajetória e fundamentos da educação ambiental. São Paulo: Cortez, 2004.

LIMA, W. de P. \& ZAKIA, M.J.B. Hidrologia de matas ciliares. In: Matas ciliares: Conservação e recuperação. (Eds): Ricardo Ribeiro Rodrigues e Hemógenes de Freitas Leitão Filho. São Paulo, Editora da Universidade de São Paulo: Fapesp, 2000. 
LIRA, O. de O. Curso de Fluoretação para operadores de Estação de Tratamento de Água. Itabirito, 2005.

LOAGUE. K.; CORWIN, D.L. e ELLSWORTH, T. R.. The challenge of predicting nonpoint source pollution. Environmental Science e Tecnology, 1998.

LOUREIRO, Carlos Frederico B. Trajetórias e Fundamentos da Educação Ambiental. $2^{a}$ ed. São Paulo. Cortez, 2006.

LOUREIRO, Carlos Frederico B. Educação ambiental transformadora. In: MINISTÉRIO DO MEIO AMBIENTE. Identidade da educação ambiental brasileira. Org. Philippe Layrargues. Brasília, 2004.

LOUREIRO, Carlos Frederico B. Educação ambiental e gestão participativa na explicitação e resolução de conflitos. Gestão em Ação/ Programa de Pós-Graduação da Faculdade de Educação da UFBA, Salvador: ISP/ UFBA. - v.7, n.1, p. 37-50, jan./abr. 2004.

LOUREIRO, Carlos Frederico B. Trajetória e fundamentos da educação ambiental. São Paulo: Cortez, 2004.

LOUREIRO, Carlos Frederico B. O movimento ambientalista e o pensamento crítico: uma abordagem política. Rio de Janeiro: Quartet, 2003.

LUCHINI, Adriana de Mello. Os Desafios à Implementação do Sistema de Gestão dos Recursos Hídricos Estabelecido pela Lei 9.433. Dissertação de Mestrado. Fundação Getúlio Vargas, 1999.

MARGALEF, R. Limnologia. Barcelona: Omega, 1983.

MARODIN, V. S.; BARBA, I. S.; MORAIS, G. A. Educação Ambiental com os Temas Geradores Lixo e Água e a Confecção de Papel Reciclável Artesanal. In: CONGRESSO BRASILEIRO DE EXTENSÃO UNIVERSITÁRIA, 2., 2004, Belo Horizonte. Anais... Belo Horizonte : Universidade Estadual de Mato Grosso do Sul - UEMS. 2004. Disponível em: < http://www.ufmg.br/congrext/Educa/WORD/Educa62a.doc>. Acesso em: 12 Set. 2013.

MAUAD, Frederico F.; LIMA, Guilherme. Planejamento Estratégico de Sistemas Hídricos. In Uso e Gestão dos recursos hídricos: Desafios Teóricos e Político-Institucionais Volume II. MARTINS, Rodrigo Constate \& VALENCIO, Norma Felicidade Lopes da Silva (Orgs) RIMA. São Carlos. 2003.

MELO, Gutemberg de Pádua. Educação ambiental para professores e outros agentes multiplicadores. João Pessoa: IBAMA, 2007.

MINISTÉRIO DA SAÚDE. Vigilância Ambiental em Saúde. Interfaces da Gestão de Recursos Hídricos e Saúde Pública. Brasília, 2004.

MORAES, D.S.de L.; JORDÃO, B.Q. Degradação de recursos hídricos e seus efeitos sobre a saúde humana. Revista Saúde Pública. Corumbá, p. 370-374, mar-2002.

NEFFA, Elza; SILVA, Luciene Pimentel da; CERQUEIRA, Luiz Fernando Flores. Sustentabilidade Dos Recursos Hídricos Dos Meios Urbano E Peri-Urbano, Educação Ambiental E Desenvolvimento Local. Rev. eletrônica Mestr. Educ. Ambient. ISSN 1517-1256, v. 26, janeiro a junho de 2011. 
Organização das Nações Unidas para a Educação, a Ciência e a Cultura (UNESCO) Disponível em <http://www.unesco.org/pt/brasilia/special-themes/education-for-sustainabledevelopment/environmental-education/\#c37579> Acesso em 30 de setembro de 2013.

OLIVEIRA, Virgênia Maria Bezzera. O Papel da Educação Ambiental na Gestão dos Recursos Hídricos: Caso da Bacia do Lago Descoberto/DF. Dissertação de Mestrado Universidade de Brasília, 2008.

OLIVEIRA-FILHO, A.T.; ALMEIDA, R.J. de; MELLO, J.M. de; GAVILANES, M.L. Estrutura fitossociológica e variáveis ambientais em um trecho de mata ciliar do córrego Vilas Boas, Reserva Biológica do Poço Bonito, Lavras (MG). Revista Brasileira de Botânica, São Paulo, v.17, n.1, p.67-85, 1994.

OPAS - Organização Pan-Americana de Saúde. Série de folhetos: Autoridades locais, Meio Ambiente e Saúde. Água e Saúde. Escritório Regional para as Américas, 1999.

PÁDUA, S.; TABANEZ, M. (orgs.). Educação ambiental: caminhos trilhados no Brasil. São Paulo: Ipê, 1998.

PEREIRA, V.P. Solo: manejo e controle de erosão hídrica. Jaboticabal: FCAV, 1997.PEREIRA, A. B.; Aprendendo Ecologia Através da Educação Ambiental, ed. Sagra-DC Luzzatto: Porto Alegre, 1993.

PINHEIRO, José Ivam; SANTOS, Esmeraldo Macedo dos; MACÊDO, Rose Meire Penha Revorêdo de; JÚNIOR, Sérgio Marques. Proposta de Educação Ambiental e Estudos de Percepção Ambiental na Gestão do Recurso Hídrico. Universidade Federal do Rio Grande do Norte Programa de Pós - Graduação em Engenharia de Produção. 2001.

PIRES, J.S.R.; SANTOS, J.E. dos. Bacias hidrográficas: integração entre meio ambiente e desenvolvimento.Ciência Hoje, São Carlos, v.19, n.10, p.4-45, 1995.

PONTUSCHKA, N. N. et al. Para ensinar e aprender Geografia. São Paulo: Cortez, (Coleção Docência em Formação. Série Ensino Fundamental), 2007.

Programa das Nações Unidas para o Desenvolvimento (PNUD). Relatório do desenvolvimento humano 2003. Objetivos do desenvolvimento do milênio: um pacto entre nações para eliminar a pobreza humana. Disponível em: <http://www.pnud.org.br/hdr>. Acesso em: 13 de outubro de 2013.

REBOUÇAS, A.C. Água no Brasil: Abundância, desperdício e escassez. Revista Bahia Análise e Dados, número especial, 2003.

REBOUÇAS, A.C. Águas doces no Brasil: capital ecológico, uso e conservação. 2.ed.rev. São Paulo: Escrituras, 2002.

REBOUÇAS, A.C. Água Subterrânea: fonte mal explorada no conhecimento e na sua utilização. Água em Revista: Revista Técnica e Informática da CPRM. n.8, 1997.

REIGOTA, M. Desafios à educação ambiental escolar. In: JACOBI, P. et al. (orgs.). Educação, meio ambiente e cidadania: reflexões e experiências. São Paulo: SMA, 1998. p. 43-50. 
REIGOTA, M. O que é Educação Ambiental. São Paulo: Brasiliense, 1994.

RIBEIRO, J. Propriedade das águas e o registro de imóveis. In: Vladimir Passos Freitas (Org.). Águas - Aspectos jurídicos e ambientais. $2^{a}$ ed. Curitiba: Juruá, p. 29-49, 2003.

ROCHA, G.A.A. Construção do sistema Paulista de gestão dos recursos hídricos. Disponível em: <http://abrh.org> . Acesso: 15 de outubro de 2013.

SAITO, C. H. "Cocô na praia, não!" - Educação Ambiental, ensino de Ciências e lutas populares. Ambiente \& Educação, Rio Grande, n. 4, p. 45-57, 1999.

SATO, M; CARVALHO, I.C.M. Educação ambiental: pesquisa e desafios. Porto Alegre: Artmed, 2005.

SATO, M. Educação para o ambiente amazônico. Tese (Doutorado em Ecologia e Recursos Naturais) - Centro de Ciências Biológicas e Saúde, Universidade Federal de São Carlos, São Carlos, 1997.

SECRETARIA DE RECURSOS HÍDRICOS-SRH. Banco Interamericano de Desenvolvimento. Minuta do caderno setorial de recursos hídricos: setor agropecuário e recursos hídricos. Relatório Técnico. Brasília, 2005.

SEGURA, D.S.B. Educação Ambiental nos projetos transversais. In: SORAIA S. de M.; TRAJBER, R. Vamos cuidar do Brasil: conceitos e práticas em educação ambiental na escola. Ministério da Educação, Coordenação Geral de Educação Ambiental: Ministério do Meio Ambiente, Departamento de Educação Ambiental: UNESCO, 2007.

SETTI, Arnaldo Augusto. Introdução ao Gerenciamento de Recursos Hídricos. Brasília; Agência Nacional de Energia Elétrica; Agência Nacional de Águas, 2001.

SIH/ANEEL-AGÊNCIA NACIONAL DE ENERGIA ELÉTRICA. Informações hidrológicas brasileiras. Brasília: ANEEL, 1999.

SILVA C. M., MARTINELLI C., Silva C. D. Educação ambiental: Uma necessidade para os alunos do ensino fundamental, 2007. Disponível em:< http://www.amigosdanatureza.org.br/noticias/358/trabalhos/398.bmambiental.pdf $>$. Acesso em: 12 nov. 2013.

SHIKLOMANOV, I.A. Comprehensive assessment of fresh resources of world; assessment of water resources and water availability in the world, WMO/SEI,1997.

SORRENTINO, Marcos; TRAJBER, Rachel; FERRARO JUNIOR, Luiz Antonio. Educação ambiental como política pública. Educação e Pesquisa, São Paulo, v.31, n.2. p. 285299. maio/ago.2005.

TAMAIO, I. O professor na construção do conceito de natureza: uma experiência de Educação Ambiental. São Paulo: Annablume: WWF, 2002.

THAME, A.C.M. Fundamentos e antecedentes. In: A cobrança pelo uso da água, Thame, A.C.M et al., São Paulo: Instituto de Qualificação e Editoração, 2000.

THIOLLENT, M. Metodologia da pesquisa-ação. 14. ed. São Paulo: Cortez, 2005. 
THOMAS, Shaji. Educação Ambiental Participativa na Promoção da Cidadania: Experiência das Comunidades Urbanas do Eixo-Forte na Cidade de Santarém - PA. Dissertação (Mestrado). Universidade da Amazônia Curso de mestrado em Desenvolvimento e Meio Ambiente Urbano, 2010.

TOZONI-REIS, M. F. C. Pesquisa-ação: compartilhando saberes. Pesquisa e ação educativa ambiental. In: FERRARO JR., L.A. (Org.). Encontros e caminhos: formação de educadoras (es) ambientais e coletivo educadores. Brasília: Ministério do Meio Ambiente, 2005. Disponível em: <http://mma.gov.br/port/sdi/ea/og/pog/arqs/encontros.pdf.> Acesso em: 12 nov.2013.

TUNDISI, José Galizia. Novas perspectivas para a gestão dos recursos hídricos. Revista USP, São Paulo, nº 70, junho/agosto 2006.

TUNDISI, José Galizia. Água no século XXI: enfrentando a escassez. 2ed. São Carlos: RiMa, 2005.

TUNDISI, José Galizia \& TUNDISI, Takaka Matsumura. A Água. Série Folha Exolica. Publifolha, São Paulo, 2005.

TUNDISI, José Galizia. Água no século XXI: enfrentando a escassez. Ed. Rima, São Carlos, SP, 2003.

TUNDISI, José Galizia. A utilização do conceito de bacia hidrográfica como unidade para atualização de professores de Ciências e Geografia: o modelo Lobo (Broa) - Brotas/ Itirapina. In: . (Org.) Liminologia e manejo de represas. São Carlos: USP, 1988.

UNESCO-WORLD WATER ASSESSMENT PROGRAMME. International Year of Planet Earth. UNESCO Publishing, Paris, 2009.

VARGAS, Marcelo Coutinho; VALENCIO, Norma Felicidade Lopes da Silva; MIRANDA, Cristiani Olga. O Processo de Interiorização do Desenvolvimento e Suas Implicações ao Acesso e Uso da Água pelo Cidadão: Desafios Econômicos, Sociais e PolíticoInstitucionais do Caso Paulista. In Uso e Gestão dos recursos hídricos: Velhos e Novos Desafios Para a Cidadania. MARTINS, Rodrigo Constate; VALENCIO, Norma Felicidade Lopes da Silva;

LEME, Alessandro André (Orgs). $2^{\circ}$ Ed. RIMA. São Carlos. 2004.

VAZHEMIN, I.G. Chemical composition of natural waters in the VYG river basin in relation to the soil of Central Karelia. Soviet Soil Science, Silver Spring, v.4, n.1, p.90-101, 1972.

VENANCIO, Diego Luis; Kurtz, Fábio Charão. Evolução da legislação sobre o Meio Ambiente e o processo de valoração econômica da água no Brasil. Ambiência - Revista do Setor de Ciências Agrárias e Ambientais V. 5 N. 1 Jan./Abr. 2009.

World Health Organization (WHO). Arsenic and arsenic compounds. International Programme on Chemical Safety, Geneva, 2001.

ZANZARINI, Ronaldo Milani; ROSOLEN, Vânia. Mata Ciliar e Nascente no Cerrado Brasileiro - Análise e Recuperação Ambiental. 2007. Disponível 
em<http://observatoriogeograficoamericalatina.org.mx/egal12/Procesosambientales/Impactoa mbiental/72.pdf>. Acesso em: 09 nov. 2013. 